\title{
Posttraumatic eyebrow reconstruction with hair-bearing temporoparietal fascia flap
}

\author{
Reconstrução de sobrancelha após trauma com retalho de fáscia temporoparietal \\ associado à ilha de pele de couro cabeludo \\ Rafael Denadai ${ }^{1}$, Cassio Eduardo Raposo-Amaral ${ }^{1}$, Frederico Figueiredo Marques ${ }^{1}$, \\ Cesar Augusto Raposo-Amaral ${ }^{1}$
}

\begin{abstract}
The temporoparietal fascia flap has been extensively used in craniofacial reconstructions. However, its use for eyebrow reconstruction has been sporadically reported. We describe a successfully repaired hair-bearing temporoparietal fascia flap after traumatic avulsion of eyebrow. Temporoparietal fascia flap is a versatile tool and should be considered as a therapeutic option by all plastic surgeons.
\end{abstract}

Keywords: Eyebrows/abnormalities; Eyebrows/surgery; Flaps; Case reports

\section{RESUMO}

0 retalho de fáscia temporoparietal tem sido usado em inúmeras reconstruções craniofaciais. No entanto, sua utilização para a reconstrução de sobrancelha tem sido relatada esporadicamente. Descreve-se aqui o reparo com retalho de fáscia temporoparietal associado à ilha para a reconstrução de sobrancelha, após avulsão traumática, realizado com sucesso. 0 retalho de fáscia temporoparietal é uma ferramenta versátil e deveria ser considerada no arsenal terapêutico de todos os cirurgiões plásticos.

Descritores: Sobrancelhas/anormalidades; Sobrancelha/cirurgia; Retalhos; Relatos de casos

\section{INTRODUCTION}

Eyebrow defects secondary to trauma, burn injuries, or ablative surgeries require challenging reconstructive procedures. ${ }^{(1-3)}$ Different eyebrow reconstruction techniques have been described worldwide such as cosmetic tattoo, composite hair graft (micro-grafts, strip grafts, and punch graft), subcutaneous pedicle island flap, temporoparietal fascia flap (TPF), and interpolation scalp flap in two stages. ${ }^{(1-5)}$ Hair graft is the most widely used technique; ${ }^{(5)}$ however, because of the influence of circulatory condition of the recipient bed, its use on extensive scar areas becomes impaired. ${ }^{(1,2)}$ Scalp flaps are also used, however they require staging procedures. Hair-bearing TPF flap has been used by a single surgical procedure as an alternative for reconstruction of regions with low vascularization..$^{(1,2)}$

This study reported a case of a patient with a posttraumatic left eyebrow defect associated with a large area of scarred tissue that was successfully reconstructed with a hair-bearing TPF flap.

\section{CASE REPORT}

A 27-year-old woman with complete soft tissue avulsion of her left forehead was referred to our service 2 years after a severe motor vehicle crash. She underwent in another hospital 17 months before a delayed scalp flap for 30 days to promote granulation subsequently 
followed by full thickness skin graft over frontal bone. In addition, no attempt to reconstruct the eyebrow was previously performed. At physical examination we noticed absence of frontalis muscle in the implanted region, lack of functioning of the upper eyelid elevator muscle and complete left eyelid ptosis. The patient also had absence of left eyebrow and an extensive scar tissue on the site (Figure 1A). Further evaluations revealed she had traumatic superior orbital fissure syndrome; characterized by ophthalmoplegia, ptosis, proptosis, and hypesthesia in the forehead and upper eyelid regions. ${ }^{(6)}$ Her vision was impaired due to non-treatment of the syndrome in the other hospital. An electromyography showed inactivity of left upper eyelid elevator muscle.

\section{Operative procedure}

We planned a composite TPF flap with a longitudinal island of scalp (Figure 2) as follows. A coronal incision was carefully marked away from the path of the superficial temporal artery (STA) identified using a Doppler device. The distance between the rotation axis of the flap and the eyebrow defect was marked with a blue marking ink and transferred to the scalp, showing the length of the TPF flap to be harvested. The dimension of the contralateral eyebrow was also transferred to the scalp, showing the region of the scalp, simulating the ipsilateral eyebrow, and an initial incision was carried out at the distal parietal portion of the coronal marking.
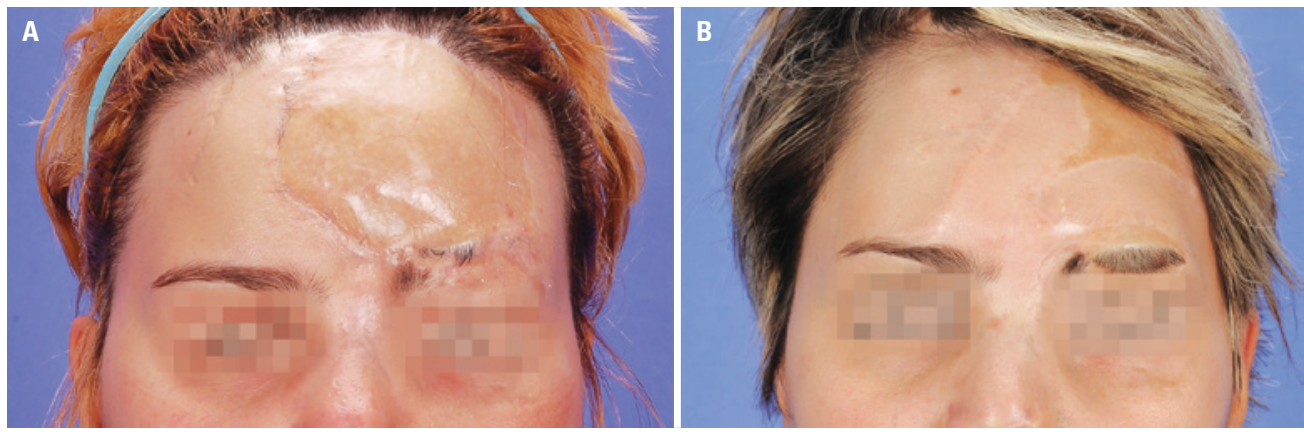

Figure 1. (A) Preoperative appearance of the patient's periorbital region. Absence of left eyebrow and mismatching skin color over forehead due to the full thickness skin graft. (B) Appearance of the left eyebrow with a satisfactory hair growth 2 years after surgery
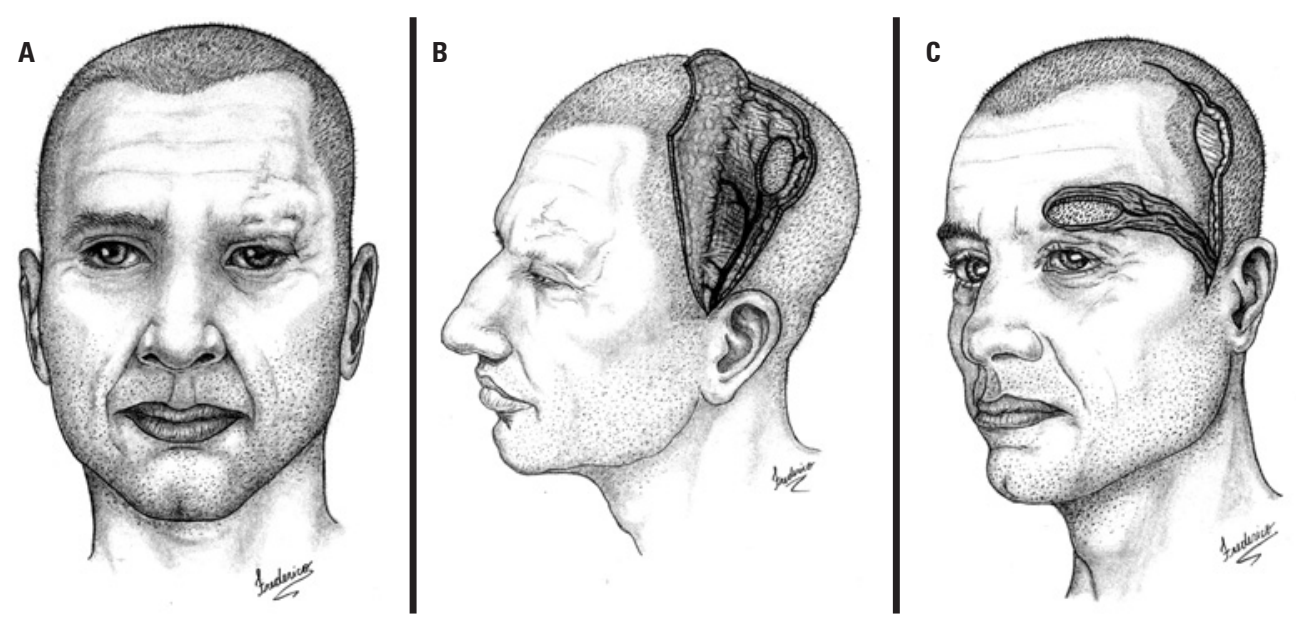

Source: Frederico F. Marques (responsible for drawing the scheme).

Figure 2. (A) Absence of left eyebrow. (B) Schematic representation of eyebrow reconstruction with hair-bearing temporoparietal fascia flap. The temporoparietal fascia flap was planned in such way that the skin island was left on the flap of the posterior branch of the superficial temporal artery. (C) Rotation of the hair-bearing temporoparietal fascia flap to the eyebrow defect, before making the subcutaneous tunnel 
The island of hair-bearing scalp flap was incised up to the left ear, however, preserving the STA. After wide elevation of the scalp flap at the subcutaneous plane, the STA trajectory was fully visualized and the distal parietal portion of this vessel was ligated distally from hair-bearing island scalp flap. The thin STA, including the hair-bearing island scalp flap, was carefully elevated toward its axis of rotation. An incision was performed on the left eyebrow region and the TPF flap rotated to this area through a subcutaneous tunnel between the base of the pedicle and the eyebrow defect.

We adapted the hair-bearing island scalp flap into the incised space of the eyebrow region (when the contralateral eyebrow design was used as a template) and sutured it using nylon threads (Johnson \& Johnson, São José dos Campos, São Paulo, Brazil). The scalp donor site was closed directly. A vacuum drain was placed for 24 hours.

Concurrent with the TPF flap the patient underwent left frontal bone reconstruction using calvarial grafts. The patient was also submitted other surgical procedures, one to reconstruct her left nasal wing with an expanded two-stage forehead flap and another to remove the full thickness skin graft over her forehead with an expanded temporal skin flap.

No procedure to restore the upper eyelid functioning was performed because of the severity of the soft tissue damage in patient's upper third of the face (absence of the frontalis muscle and impaired function of upper eyelid elevator muscle).

\section{Outcomes}

The postoperative was uneventful with minor morbidity in donor site. During the 24-month follow-up period, no complication was seen and a satisfactory aesthetic result was achieved (Figure 1B). No improvement in symptoms related to superior orbital fissure syndrome was seen.

\section{DISCUSSION}

Given the clinical situation reported here, the ideal would be first restore the functioning of her left upper eyelid. However, it was impossible because of the absence of frontalis muscle and complete denervation of upper eyelid elevator muscle. Because the patient complained about the absence of eyebrow, we decided to reconstruct it with a composite TPF flap.

The choice of a particular technique for the eyebrow reconstruction should be individualized. ${ }^{(4)}$ Grafts are more suitable for women while flaps seem to be the best options for men. ${ }^{(4)}$ However, as grafts have inadequate density ${ }^{(2,3)}$ and inserting them may be difficult because of thin, scar, or previously grafted recipient area, ${ }^{(2)}$ we and others surgeons ${ }^{(2)}$ favor the use of flap.

The TPF flap has been used in head and neck surgery, skull base reconstruction and pediatric plastic surgery. ${ }^{(7-9)}$ This flap role on eyebrow reconstruction after burn injuries and tumor resection has been acknowledged by many surgeons; $;^{(1-4,10,11)}$ however, experience remains limited on its use for posttraumatic eyebrow reconstruction. ${ }^{(2)}$

Since the first description of posttraumatic eyebrow reconstruction with island TPF flap, ${ }^{(12)}$ this technique did not gain popularity among plastic and reconstructive surgeons. We performed a comprehensive literature review of manuscripts published in English indexed in PubMed/MEDLINE and Embase using the keywords "temporoparietal fascia flap" and "superficial temporal artery" combined with "eyebrow”, "eyebrow defect” and "posttraumatic eyebrow defect". This review revealed that aforementioned pioneer study ${ }^{(12)}$ was the one using TPF flap for posttraumatic eyebrow reconstruction.

Perhaps, the complex anatomy of the temporal superficial fascia and its vascularization may inhibit the widespread use of this flap by plastic and reconstructive surgeons. However, significant advantages, as those previously described by Raffaini and Costa, ${ }^{(12)}$ showed that ultra-thin fascia can be rotated to the area of the defect without bringing additional volume to the region. The vascularized area of hair-bearing scalp works perfectly well for areas without sufficient vascularization and previous scarring tissue, in which hair follicles grafts may not work. The anatomy and trajectory of the STA should be identified to avoid an accidental injury to this vessel. The minor injury to STA during coronal incision jeopardizes the TPF flap and its subsequent use either to reconstruct the eyebrow or to coverage grafts as additional blood supply. Thus, any coronal incision used to injured bone reconstruction should always be carefully planned.

Some critics against the use of the TPF flap for eyebrow reconstruction are the unnatural hair-growth direction, complexity and time-consuming procedure and the significant time needed to surgeons gain expertise. ${ }^{(3)}$ However, several features make this flap particularly useful to reconstruct posttraumatic eyebrow defect associated with extensive scar area specially because it presents scaffold reliability, pliable contour, wide arc of pedicle rotation, highly vascular, excellent color and texture match, possibility to be used as a composite flap with hair-bearing skin, anatomical 
proximity with the eyebrows and minimal donor site morbidity. ${ }^{(2,7,11,12)}$

Despite the long learning curve, ${ }^{(3)}$ variations and applications this flap should be part of therapeutic options to all plastic surgeons.

\section{CONCLUSION}

The hair-bearing TPF flap represents a useful technique and an alternative for reconstruction using grafts. This technique was adequate for reconstruction of the complete traumatic avulsion of eyebrow associated with scar tissue in a female patient.

\section{REFERENCES}

1. Motomura H, Muraoka M, Nose K. Eyebrow reconstruction with intermediate hair from the hairline of the forehead on the pedicled temporoparietal fascial flap. Ann Plast Surg. 2003;51 (3):314-8; discussion 319-20.

2. Bozkurt M, Kulahci Y, Kapi E, Karakol P. A new design for superficial temporal fascial flap for reconstruction of the eyebrow, upper and lower eyelids, and lacrimal system in one-stage procedure: medusa flap. Ann Plast Surg. 2009;63(6):636-9.
3. Omranifard M, Doosti Ml. A trial on subcutaneous pedicle island flap for eyebrow reconstruction. Burns. 2010;36(5):692-7.

4. Motamed S, Davami B. Eyebrow reconstruction following burn injury. Burns. 2005;31(4):495-9.

5. Wang J, Fan J. Cicatricial eyebrow reconstruction with a dense-packing one- to two-hair grafting technique. Plast Reconstr Surg. 2004;114(6):1420-6.

6. Chen CT, Wang TY, Tsay PK, Huang F, Lai JP, Chen YR. Traumatic superior orbital fissure syndrome: assessment of cranial nerve recovery in 33 cases. Plast Reconstr Surg. 2010;126(1):205-12.

7. Collar RM, Zopf D, Brown D, Fung K, Kim J. The versatility of the temporoparietal fascia flap in head and neck reconstruction. J Plast Reconstr Aesthet Surg. 2012;65(2):141-8.

8. Hocaoğlu E, Özden BÇ, Aydın H. Lower eyelid reconstruction in a paediatric face: A one-stage aesthetic approach using the versatile temporoparietal fascia flap. J Plast Reconstr Aesthet Surg. 2012;65(9):e246-9.

9. Stow NW, Gordon DH, Eisenberg R. Technique of temporoparietal fascia flap in ear and lateral skull base surgery. Otol Neurotol. 2010;31(6):964-7.

10. Tsoutsos D, Gravvanis A, loannovich J. Prefabricated hair-bearing temporal flap for two different facial aesthetic subunits reconstruction: case report. Eur J Plast Surg. 2005;27(8):394-6.

11. Ozdemir R, Sungur N, Sensöz O, Uysal AC, Ulusoy MG, Ortak T, et al. Reconstruction of facial defects with superficial temporal artery island flaps: a donor site with various alternatives. Plast Reconstr Surg. 2002;109(5):1528-35.

12. Raffaini M, Costa P. The temporoparietal fascial flap in reconstruction of the cranio-maxillofacial area. J Craniomaxillofac Surg. 1994;22(5):261-7. 